\title{
CONTENTS OF BIORHEOLOGY, VOLUME 30, NUMBERS 3/4
}

\author{
Contents \\ P. Verdugo \\ iii Editor's Note \\ Y. Isogai and P. Verdugo \\ v Editorial \\ vii Introduction \\ Conference Communications
Proceedings of the Eighth International \\ Proceedings of the Eighth International
Congress of Biorheology, Yokohama City \\ Congress of Biorheology, Yo
Japan, 3-8 August 1992 \\ Poiseuille Medal Award Lecture \\ H. L. Goldsmith \\ 165 From papermaking fibers to human \\ blood cells \\ Part I \\ Symposium: Rheology of Biopolymer Gels \\ M. Djabourov, J.-P. Lechaire and \\ F. Gaill \\ 191 Structure and rheology of gelatin \\ and collagen gels \\ K. Nakamura and R. Niki \\ 207 Rheological properties of casein \\ micelle gels: The influence of \\ calcium concentration on gelation \\ induced by rennet \\ S. B. Ross-Murphy and K. P. Shatwel \\ 217 Polysaccharide strong and weak \\ gels \\ M. A. Lillie and J. M. Gosline \\ 229 The effects of polar solutes on the \\ viscoelastic behavior of elastin \\ K. Nishinari, K E. Hofmann \\ K. Kohyama, H. Moritaka, N. Nishinari \\ and $\mathrm{M}$. Watase \\ 243 Polysaccharide-protein \\ interaction: A rheological study of \\ the gel-sol transition of a gelatin- \\ methylcellulose-water system \\ Papers \\ D. Quemada \\ 253 A non-linear Maxwell model of \\ biofluids: Application to normal \\ blood \\ T. Matsuo, R. Okeda and K. Yamamoto \\ 267 Study of biofluid mechanics at \\ arterial bifurcations: Importance \\ of flow division ratio as a \\ parameter \\ S. Hasegawa, G. P. Rodgers, H. Shio, \\ A. N. Schechter and N. Uyesaka \\ 275 Impaired deformability of Heinz \\ body-forming red cells \\ M. Löw, K. Perktold and R. Raunig \\ 287 Hemodynamics in rigid and distensible \\ saccular aneurysms: A numerical study \\ of pulsatile flow characteristics \\ 299 Announcements \\ 301 Erratum \\ 303 Contents of Clinical Hemorheology, \\ Volume 13, Number 2
}

